\title{
Pesquisa sobre educação ambiental no contexto escolar: a imersão nos ambientes educativos
}

\author{
Lucia de Fátima Estevinho Guido ${ }^{1}$ \\ Melchior José Tavares Júnior ${ }^{2}$
}

Resumo: O propósito deste artigo é contribuir para as reflexões sobre a pesquisa em educação ambiental no contexto escolar por meio da problematização de metodologias de pesquisa que contemplem as especificidades desse contexto. Nessa direção, alguns aspectos foram emergentes: (1) a imersão no contexto educativo para uma apreensão abrangente da educação ambiental na escola; (2) a compreensão da concepção de educação, individual e coletiva; (3) a compreensão ampla dos desdobramentos da disciplina educação ambiental na Educação Básica; (4) a credibilidade da pesquisa no contexto escolar a partir do retorno dos resultados das pesquisas; (5) a compreensão da epistemologia com ênfase na teoria da complexidade. Embora o campo de pesquisa em educação ambiental no contexto escolar esteja sendo delimitado, consideramos que é necessário primeiro identificar as grandes questões de pesquisa no contexto escolar para então buscar métodos que forneçam respostas.

Palavras-chave: Educação Ambiental, Escola, Questões de Pesquisa.

\begin{abstract}
The aim of this paper is to contribute to enhancing the reflection on environmental education research in the school context by problematizing research methodologies that contemplate the specificities of that context. In this regard, some aspects could be observed: (1) immersion in the educational context for a comprehensive grasp of environmental education at school; (2) understanding individual and collective conceptions of education; (3) understanding the effects of environmental education as a discipline in Elementary Education; (4) research credibility in school context based on feedback of research data; (5) understanding epistemology through the theory of complexity. Although the definition of the environmental education research field in the school context is underway, we consider it necessary to first identify the key research issues in the school context and then seek methods to provide answers for them.
\end{abstract}

Keywords: Environmental Education, School, Research Issues.

${ }^{1}$ Bióloga, doutora em Educação pela Unicamp. Professora do Instituto de Biologia e do Programa de Pós-Graduação em Educação da Universidade Federal de Uberlândia. Al. dos Cajás, 300, Condomínio Jardins Roma, Bairro Jardim Nova Uberlândia Uberlândia, MG. CEP 38.412-246. E-mail: luciag@umuarama.ufu.br

2 Biólogo, doutorando em Educação (PPGDED/FACED/UFU). Professor da Fac. de Ciências Integradas do Pontal (FACIP/UFU). E-mail: profmelk@hotmail.com 


\section{A escola e a educação ambiental}

Nosso ponto de partida para discutir a pesquisa em educação ambiental no contexto escolar é a imersão nesse contexto por meio de uma visita a uma escola estadual ${ }^{3}$ da cidade de Araxá, MG. Essa visita fazia parte da programação da disciplina ${ }^{4}$ Educação Ambiental do curso de Ciências Biológicas da Universidade Federal de Uberlândia (UFU). A descrição de uma entre várias fotografias ${ }^{5}$ registradas durante a visita pode nos fornecer pistas sobre o trabalho da escola em geral e da educação ambiental lá praticada.

A foto mostra o espaço de entrada da parte administrativa da escola, uma espécie de antessala à sala dos professores, onde computadores permitem aos professores estarem conectados à internet. É uma sala retangular, paredes claras e chão de cerâmica verde. Há muitos "bilhetes" afixados no quadro de avisos, homenagens nas paredes. Chama a atenção um canto dessa antessala onde encontramos objetos dispostos um ao lado do outro: uma imagem de uma santa, uma Bíblia aberta em um suporte, uma mesinha com uma TV e um aparelho de videocassete, um suporte com revistas. Não dá para entender se a TV e o videocassete funcionam ou se apenas estão compondo uma cena em que, junto com os outros objetos, nos fornecem um entendimento da escola, sua "filosofia" de trabalho.

Uma imagem de tamanho médio de uma santa com seu manto azul claro, seu rosto doce, indica que a religião se faz presente nessa escola, não isolada em uma disciplina religiosa, mas como ponto de referência das ações desenvolvidas de alguma maneira ligadas ao pensamento cristão. A Bíblia aberta representa que a escritura também se faz presente e nesse sentido a escola mantém diálogo com outras instituições, não só com a Ciência. Também é possível perceber que a imagem protege a escola e seus funcionários, pois está na entrada da sala dos professores, e podemos inferir que a proteção se estende à pedagogia da escola.

3 A Escola Estadual Prof. Luiz Antônio Corrêa de Oliveira é considerada modelo não apenas para o município de Araxá como também para o estado de Minas Gerais e o Brasil. Ela vem ganhando o prêmio nacional de gestão educacional e obteve o primeiro lugar no estado de Minas Gerais no ano de 2008.

${ }^{4}$ A Educação Ambiental é uma disciplina obrigatória do Curso de Ciências Biológicas da UFU, tendo sido incluída como tal na última Reforma Curricular do curso, ocorrida em 2005.

5 Vários autores têm utilizado a fotografia como dispositivo para refletir sobre a escola na contemporaneidade (AMORIM, 2007; GUIMARÃES, 2009; WUNDER, 2008). Os autores citados forneceram elementos para trabalharmos com as fotografias registradas pelos alunos da universidade durante a visita à escola em Araxá. 
A partir dos outros objetos (TV, vídeo e revistas), podemos pensar em questões relacionadas aos aspectos pedagógicos da referida escola. A disposição da TV e vídeo, assim como a das revistas, mostra uma preocupação com a cultura, com a sua inserção no dia a dia da escola. Salientamos que estas considerações estão sendo colocadas a partir da análise da fotografia. Ao adentrarmos os outros espaços e estabelecermos conversas com vários integrantes da escola (professores e professoras, diretora, coordenadoras, alunos e alunas), foi possível conhecer um pouco mais sobre a escola, o que ampliou nossa percepção dos objetos e seus significados presentes na fotografia. No dia de nossa visita à escola, estava ocorrendo a II Feira Tecnológica, e toda a equipe estava reunida expondo os trabalhos realizados pelos alunos e alunas, os quais estavam dispostos em diferentes estandes. Chamou nossa atenção um estande que apresentava as atividades desenvolvidas pelo Grupo de Desenvolvimento Profissional (GDP) criado em 2004 na escola e que vem desenvolvendo projetos que agregam valores humanos embasados na ética ambiental. Em 2007, o grupo começou a desenvolver dois projetos: "Amando e preservando a vida" e "Quem ama cuida". A educação ambiental está presente no GDP em atividades ligadas ao meio ambiente, sua proteção. Atividades que poderiam ser consideradas, se vistas isoladamente, como pontuais, conservacionistas, como o plantio de árvores, visita ao criadouro conservacionista de uma empresa multinacional instalada no município, caminhada ecológica; mas elas não estão isoladas e no seu conjunto dão significado à proposta do GDP, qual seja: valorização do ser humano, do ser professor, do ser pai, mãe, aluno, aluna, família, gestão. Uma participação política oportunizada pela educação ambiental.

$\mathrm{Na}$ exposição do GDP na feira, percebemos também uma preocupação com o bem-estar do professor. Foi possível observar mais um significado da presença da televisão, do vídeo, das revistas, dos computadores disponíveis aos professores na antessala descrita a partir da fotografia. Uma escola que se preocupa com o bem-estar do professor disponibiliza televisão, vídeo, revistas para tornar sua estadia na escola mais agradável? No pátio da escola, também

${ }^{6}$ A justificativa desses projetos está descrita no sítio da escola na internet: "Considerando a necessidade de práticas solidárias e fraternas no mundo contemporâneo, propomos o desenvolvimento de um projeto com temática sobre Educação em Valores Humanos e Formação Ética". Assim, o Projeto Amando e Preservando a Vida vem contemplar o corpo docente, discente e a comunidade escolar numa ótica global e ambiental; evidenciadas no século XXI, inserindo ações eficazes direcionadas às relações humanas em seus aspectos culturais, históricos, físicos, sociais e econômicos. Acreditamos que é possível melhorar o meio ambiente mudando nossos hábitos cotidianos (educadores, alunos, famílias e comunidade). Esperamos que nossos alunos sejam multiplicadores das ações vivenciadas pelo Projeto, pois CUIDAR, RESPEITAR e PRESERVAR é AMAR (http://www.escolapolivalente.com.br/gdp.htm,,acesso em 20/10/2009). 
encontramos um espaço para os jornais, as revistas, um sofá. Alunos e alunas estão habituados a usar e cuidar desse espaço.

Retornando à educação ambiental realizada pela escola, é possível pensar uma série de questões relativas à pesquisa em educação ambiental no contexto escolar e que trazemos para este GDP (Grupo de Discussão de Pesquisas). A primeira delas se refere à importância de adentrarmos o espaço escolar para investigar a educação ambiental ali realizada. Foi preciso ir até a escola conversar com professores, professoras, alunos, alunas, equipe pedagógica e demais funcionários, visitar a feira, acessar o sítio da escola na internet e olhar os registros fotográficos para perceber que as atividades e os projetos não são pontuais; ao contrário, estão inseridos no Projeto Político-Pedagógico da escola.

Tristão (2004, p. 48), em trabalho sobre a educação ambiental no contexto escolar, comenta a importância de conhecer o cotidiano escolar realizando uma "escuta sensível" 7 para "conectar-se com seus protagonistas em suas dinâmicas não só instrumentais, racionais, mas também emocionais”. Essa escuta sensível permitiu a realização de uma pesquisa que vai além das aparências, revelando uma complexa rede de práticas, saberes e significados que vão se constituindo para além do conhecimento escolar.

Mesmo não se caracterizando como uma pesquisa, como Tristão (2004) relata em seu texto - realizamos apenas uma visita à escola -, foi possível ouvir, sentir e refletir sobre a educação ambiental realizada na escola. Será que um levantamento via questionário teria fornecido elementos suficientes para conhecermos tal educação ambiental? Os projetos isolados poderiam mostrar trabalhos pontuais, imediatamente situados na visão conservacionista?

\section{Pesquisas em educação ambiental: caminhos trilhados}

A partir das reflexões apresentadas no tópico anterior, outras questões começaram a aparecer: os levantamentos estatísticos realizados nas escolas para mapear as que realizam educação ambiental conseguem mostrar um quadro do que realmente acontece nesses locais? Conseguem os protocolos das pesquisas captar os significados desses acontecimentos e situá-los no contexto mais amplo da filosofia e do projeto escolar?

Discussões já realizadas em outros GDPs em EPEAs anteriores (GUERRA; GUIMARÃES, 2007) apontam que os levantamentos realizados por

7 Tristão (2004) faz referência a Barbier (1985) para fundamentar a ideia de escuta sensível. 
pesquisas de porte nacional ${ }^{8}$ para um mapeamento da presença da educação ambiental nas escolas podem ter os resultados um pouco distorcidos, uma vez que as respostas a esses questionários são dadas na sua maioria por pessoas responsáveis pela gestão escolar, nem sempre envolvidas com os trabalhos de educação ambiental. Segundo o resultado das discussões do GDP em 2005, outro fator pode enfraquecer a confiabilidade dos dados: a direção da escola tem sempre a preocupação em passar uma imagem positiva da escola. Outras questões levantadas pelo grupo foram: "Que tipo de prática a escola desenvolve? As intervenções pedagógicas se caracterizam por ações pontuais ou comportamentais? Ou são práticas efetivas?”.

Os dados apresentados pelo Instituto Nacional de Estudos e Pesquisas Educacionais Anísio Teixeira (Inep) foram discutidos no Grupo de Trabalho (GT) Educação Ambiental da Associação Nacional de Pós-Graduação em Educação (ANPEd) no ano de 2005 e novos questionamentos surgiram e foram considerados pela equipe do Inep responsável pela pesquisa, a saber: "Mas que Educação Ambiental é esta praticada nas escolas? Quais são as práticas pedagógicas utilizadas pelas escolas para inserir Educação Ambiental no currículo? Que mudanças estão ocorrendo no cotidiano escolar em decorrência dessa inserção? Há um impacto significativo dessas práticas na comunidade?” (TRAJBER; MENDONÇA, 2006, p. 14).

Essas demandas levaram o Inep a incluir uma segunda etapa na pesquisa iniciada em 2006 com a seguinte pergunta: "O que estão fazendo as escolas que dizem estar fazendo Educação Ambiental?”. Resultados parciais dessa pesquisa foram apresentados na $30^{a}$ Reunião Anual da ANPEd no GT Educação Ambiental. Conforme Lima (2007), um dos objetivos do estudo é colher dados que deverão fundamentar "pesquisas acadêmicas e políticas públicas de apoio à educação ambiental no contexto escolar". Tal objetivo está diretamente ligado aos objetivos deste GDP, que, ao longo dos vários encontros, vem sistematizando a pesquisa em educação ambiental no contexto escolar.

O principal instrumento da pesquisa foi um questionário-teste organizado com base em três eixos: "as práticas pedagógicas utilizadas pelas escolas para inserir educação ambiental no currículo, as mudanças que estão ocorrendo no cotidiano escolar em decorrência dessa inserção e o impacto dessas práticas na comunidade". Com o resultado desta pesquisa, foi possível dar

8 Pesquisa realizada pelo Instituto Nacional de Estudos e Pesquisas Educacionais Anísio Teixeira (Inep) em parceria com a Secretaria de Educação Continuada, Alfabetização e Diversidade (Secad/MEC) e com a Associação Nacional de Pesquisa em Educação (ANPEd). Seu objetivo segundo relatório apresentado pelo grupo responsável pela pesquisa, "é entender melhor como a Educação Ambiental é processada e significada nos diferentes contextos escolares”. (VEIGA; AMORIM; BLANCO, 2005, p. 7). 
visibilidade a uma diversidade de trabalhos, projetos e práticas de educação ambiental desenvolvidos pelas escolas. Lima (2007) enfatiza que muitos trabalhos eram pouco conhecidos pelo próprio município e que ao adquirirem visibilidade poderão servir de exemplo a outras escolas. Esse comentário realizado pela autora vai ao encontro da fala da diretora da escola de Araxá que visitamos e a qual comentamos na introdução deste texto. Merece destaque outro aspecto considerado por Lima (2007) e que também observamos quando adentramos o espaço escolar para conhecer "as praticas de educação ambiental” realizadas. Nas palavras da autora:

A experiência de visitar escolas e entrevistar profissionais de educação mostrou que os trabalhos de EA realizados são, quase sempre, fruto de esforços pessoais e/ou coletivos de profissionais que enfrentam um sem número de problemas e que precisam ser vistos e apoiados [...] Ao ouvir como os professores pensam e realizam a EA, entendi que são inúmeras e, sobretudo, complexas as suas formas de inserção nos currículos escolares. Sobretudo, vislumbrei os saberes dos professores que, quase sempre na adversidade, conseguem dar visibilidade ao potencial dos seus alunos, estimulando-os a produzirem exposições, peças de teatro, textos, músicas, cartazes e maquetes e, a partir destas atividades, transmitir uma grande gama de conhecimentos relacionados à EA (LIMA, 2007, p. 15).

No IV EPEA (2007), o GDP Educação Ambiental no contexto escolar discutiu várias questões e deu prioridade:

(i) à construção do projeto político-pedagógico da escola, ou seja, a educação ambiental se define a partir de um projeto político-pedagógico [...] (ii) às tensões entre disciplinaridade e interdisciplinaridade nas práticas curriculares escolares; (iii) à ambientalização dos currículos escolares considerando a integração entre perspectivas macro e micro de análise, quer dizer, priorizando as análises que se detenham nas relações entre as perspectivas como as das propostas oficiais e aquelas práticas curriculares do cotidiano escolar; (iv) às concepções diversas de conhecimentos, como por exemplo, da pedagogia, da física, da química, da biologia, etc.; (v) aos trabalhos escolares que partem de projetos; e (vi) às políticas públicas educacionais (SILVA; GOMES, 2008, p. 251-252).

Os autores referidos acima também comentaram que uma preocupação do GDP do IV EPEA está relacionada ao retorno das pesquisas realizadas no contexto escolar para os próprios "atores sociais da escola". E, quando a 
pesquisa no contexto escolar envolver a própria pratica - pesquisa de caráter intervencionista -, devem ser observados os cuidados para que o trabalho se caracterize como uma pesquisa, incluindo-se o distanciamento para o amadurecimento teórico do pesquisador.

No III EPEA, os resultados do GDP foram sintetizados por Guerra e Guimarães (2007) e estão pautados em questões que podem servir de balizamento das iniciativas que devem ser buscadas. São elas:

- Implantar programas de formação em EA para docentes das Universidades, uma vez que um bom número de professores universitários também não sabe "o que é educação ambiental";

- Aproximação entre Universidades, ONGs e Escolas para o fortalecimento do movimento ambiental, que inclui a constituição de Redes Sociais que vêm surgindo ou se expandido na sociedade;

- As questões de pesquisa devem ser elaboradas na interface da Universidade e da escola por meio de referenciais teóricos do campo da educação referentes à Escola, como: cotidiano escolar; currículo; conhecimentos escolares; formação e saber docente (buscar um diálogo entre eles também é um desafio para a EA multirreferencialidade);

- Criar mecanismos para pesquisas acessíveis à realidade da escola. Reafirmar a necessidade no campo da EA da utilização de metodologias qualitativas, que incorporam a subjetividade presente na realidade. É importante que a pesquisa aborde materiais didáticos, programas e outros materiais para a escola (GUERRA; GUIMARÃES, 2007, p. 163).

Nota-se que as experiências de Tristão (2004) encontram ressonância nas recomendações acima, que, de fato, dão sentido à vivência que tivemos na escola em Araxá, chamando a atenção para que a pesquisa no ambiente educativo seja realizada com toda a abrangência e sensibilidade que a temática exige.

\section{Pesquisas em educação ambiental: de olho no horizonte...}

Para dar mais consistência à nossa discussão no GDP do V EPEA, realizamos um novo levantamento na perspectiva de ampliar os já realizados nos GDPs sobre educação ambiental no contexto escolar nos EPEAs anteriores (GUERRA; GUIMARÃES, 2007; SILVA; GOMES, 2008).

Nossa atenção se deteve nos trabalhos apresentados no IV EPEA (2007) e nas teses e dissertações defendidas em 2007 e que estão cadastradas no 
banco de dados da Coordenação de Aperfeiçoamento de Pessoal de Nível Superior (CAPES). As pesquisas apresentadas no IV EPEA foram esquadrinhadas a partir da leitura dos resumos disponíveis no Caderno de Programação e Resumos. O levantamento de teses e dissertações do banco de dados da CAPES foi realizado por palavras-chave. Referências em pesquisas envolvendo o "estado da arte" na educação ambiental no Brasil nos orientaram na escolha dos critérios para analisar tais resumos (LORENZETTI; DELIZOICOV, 2006). A análise consistiu em verificar o local onde as pesquisas foram desenvolvidas, os tipos de pesquisa, os referenciais utilizados, os instrumentos de coleta de dados e as temáticas trabalhadas. Também nos pautamos nas sugestões apresentadas pelos GDPs anteriores.

É importante lembrar que apenas o resumo foi apreciado e que nem sempre ele oferece dados suficientes para um entendimento amplo da pesquisa, conforme já relatado por Kawasaki, Matos e Motokane (2006) em pesquisa realizada sobre o perfil do pesquisador em educação ambiental a partir dos inscritos no I EPEA e do Caderno de Resumos do referido evento.

Dos 87 trabalhos publicados no IV EPEA, 29 são pesquisas sobre a educação ambiental no contexto escolar. Entre essas, chama nossa atenção o fato de mais da metade das pesquisas estar situada em cidades do Sudeste, com predominância no estado de São Paulo. Kawasaki, Matos e Motokane (2006) encontraram o mesmo resultado em relação à predominância da região Sudeste, sobretudo do estado de São Paulo, nos trabalhos apresentados no I EPEA. Esses autores comentam que, apesar da predominância do estado de São Paulo, o evento se caracteriza como nacional pela presença de 19 estados e de todas as regiões brasileiras. Em relação ao número de trabalhos que discutem a temática educação ambiental no contexto escolar, os números encontrados no I EPEA são próximos a esta análise.

Retornando aos trabalhos do IV EPEA, a maior parte direciona o olhar para alunos e professores, enfatizando as concepções, as mudanças de atitudes, as relações entre propostas oficiais e as que de fato ocorrem. Entretanto, parecem não abranger o Projeto Político-Pedagógico da instituição educativa, tampouco a ambientalização curricular, o que justifica as sugestões do próprio GDP daquele ano, conforme citado anteriormente. Apesar de as pesquisas de natureza intervencionista ainda não possuírem uma ampla aceitação, especialmente relacionada à questão teoria e prática, é possível que nos próximos anos esses trabalhos venham a realizar uma investigação situada e abrangente. A tímida freqüência desse tipo de pesquisa também foi verificada nos EPEAs anteriores por Daniel e Marin (2007). 
A maior parte das pesquisas se mostrou abertamente de natureza qualitativa, sem haver uma clareza conceitual quer do campo da educação, quer da educação ambiental. Outros tipos de pesquisa, como a bibliográfica, o estudo de caso e a etnográfica, também aparecem acompanhadas de seus fundamentos teóricos. Cavalari, Santana e Carvalho (2006, p. 170), em pesquisa realizada sobre as concepções de educação e de educação ambiental a partir dos trabalhos apresentados no I EPEA, constataram "que tais concepções nem sempre são apresentadas de forma explícita [...] Assim foi necessário enveredar pelos textos, buscando elementos que pudessem dar repostas às nossas indagações". Ressaltamos que nossa intenção é buscar elementos que provoquem reflexões a serem trazidas para o GDP; não tivemos pretensão de esmiuçar os textos apresentados no IV EPEA.

No banco de dados da CAPES, encontramos no ano de 2007 um total de 225 teses e dissertações sobre educação ambiental, sendo que apenas 15 estão envolvidas com a temática educação ambiental escolar. Esses 15 estudos contemplam todas as regiões do país, com exceção da região Norte. Contudo, nenhuma região apresentou um número mais significativo de pesquisas (a região Sudeste apresentou um número um pouco acima das demais regiões). Quando comparamos o banco de dados da CAPES com as apresentações nos EPEAs, percebemos um número reduzido de pesquisas envolvendo a temática educação ambiental no contexto escolar no primeiro. Esse resultado pode estar relacionado aos dados também já levantados de que a região mais presente no referido evento ao longo dos seus quatro anos é a região Sudeste, já que no banco de teses praticamente todas as regiões foram contempladas.

A maioria dos resumos não esclarece os requisitos básicos para que a pesquisa possa ser identificada (tipologia, fundamentação, instrumentos de coleta de dados): de 15 resumos, apenas quatro forneceram todos esses dados. Os itens mais presentes são os instrumentos de coleta de dados e a temática abordada; a fundamentação teórica nem sempre é explicitada.

Chamaram a atenção os trabalhos que realizaram análise documental como instrumento de coleta de dados. Em dois houve a preocupação com o Projeto Político-Pedagógico da Escola, e na maioria dos resumos a preocupação com tal projeto aparece com maior frequência, seja nos resultados da pesquisa, seja na fundamentação teórica. Lembramos que essa preocupação não aparece nos trabalhos relativos à educação ambiental no contexto escolar apresentados no IV EPEA, mas foi eleita como tema prioritário no GDP referente a essa temática no evento. A pesquisa participante e a pesquisa-ação são consideradas, mas ainda estão restritas a três trabalhos; o estudo de caso predominou com 
quatro trabalhos e em quatro resumos não foi possível perceber a tipologia da pesquisa.

Quanto às questões e sugestões colocadas pelos GDPs anteriores, o envolvimento com o currículo escolar aparece em vários resumos analisados, ao passo que a formação de professores é apontada apenas como resultado. Em alguns resumos, é mencionada a pouca participação do professor na pesquisa. Apenas um resumo explicita o envolvimento com a formação continuada, embora na maioria das pesquisas que se utilizou da entrevista como instrumento de coleta de dados esta tenha sido realizada com os professores.

Não encontramos nos resumos referências à interdisciplinaridade e à transdisciplinaridade, assim como há uma ausência dos temas ambientalização curricular e programas de formação em educação ambiental para docentes das universidades, conforme sugerido nos últimos GDPs.

Os dados até aqui apresentados permitiram consolidar o que foi apresentado como proposta de reflexão no GDP do V EPEA: os resumos das pesquisas não apresentam dados suficientes para uma perfeita/completa compreensão das mesmas; a importância do envolvimento da pesquisa com o Projeto Político-Pedagógico da escola; o aligeiramento das pesquisas, em especial das que são desenvolvidas nos cursos de especialização e de mestrado; a resistência dos pesquisadores em adentrar os espaços escolares como um elemento discreto, mas capaz de influenciar a frequência e a natureza das pesquisas sobre educação ambiental nas instituições educativas.

Por último, para compor nossa proposta de reflexão no GDP, abordaremos uma questão que consideramos polêmica no que se refere à educação ambiental no contexto escolar: a criação ou não de uma disciplina que aborde diretamente a educação ambiental no currículo escolar.

Desde 1999, quando a Política Nacional de Educação Ambiental (PNEA) foi promulgada, vários projetos de lei (PL), ainda em tramitação, propuseram que a temática fosse instituída como uma disciplina na Educação Básica. É o caso do PL 3681/2008, do deputado José Linhares (PP-CE), e do PL 4358/2008, do deputado Homero Pereira (PR-MT). Entretanto, nesses dez anos de PNEA, o que se observou foi sua intensa institucionalização nos estados ${ }^{9} \mathrm{e}$

${ }^{9}$ No estado do Amazonas, a proposta para a inclusão da disciplina Educação Ambiental e Desenvolvimento Sustentável na rede pública prevê um mínimo de 144 horas/aula; já no Ceará, essa carga horária está prevista somente para o Ensino Médio, ficando o Ensino Fundamental com um mínimo de 72 horas/aula. No Maranhão, a disciplina deverá ocorrer na rede pública como uma atividade de extensão. 
nos municípios ${ }^{10}$, tendo como principal mecanismo os projetos oriundos das assembleias estaduais e câmaras municipais.

$\mathrm{Na}$ maioria dos projetos, o décimo artigo da Lei 9795, que instituiu a PNEA, foi apresentado como justificativa para a proposição da temática como disciplina na Educação Básica. Entretanto, o primeiro parágrafo desse mesmo artigo recomenda que a temática não deve ser implantada como disciplina. A inclusão da disciplina também vem sendo justificada por ser um espaço-tempo no qual os conhecimentos sobre a questão ambiental podem ser disponibilizados de forma mais objetiva, proporcionando uma base a partir da qual a interdisciplinaridade poderia emergir. Entretanto, a interdisciplinaridade ainda é um projeto de reconstrução do conhecimento, constituindo-se mais numa necessidade percebida do que propriamente numa prática palpável.

Essas iniciativas chamam a atenção para a tendência política da educação ambiental que defende a necessidade de políticas públicas capazes de instalar a temática nas instituições educativas de forma efetiva, superando assim a contemplação da temática por simples percepção ou declaração de sua presença no ambiente escolar. Se por um lado as políticas públicas podem contribuir muito para o desenvolvimento da temática na Educação Básica, por outro os desdobramentos desse processo precisam ser bem compreendidos. Nesse sentido, apresentamos algumas ponderações que podem ser úteis na pesquisa sobre a temática no contexto escolar:

(1) Por desconhecimento da lei, modismo ou outra razão, as propostas parecem permitir que a educação ambiental alcance a escola na forma disciplinar. Entretanto, essa condição pode reforçar ainda mais a fragmentação dos saberes. Em alguns casos, a temática passou a fazer parte da disciplina de Ciências, renomeando a mesma para Ciência e Educação Ambiental; (2) As propostas parecem estar orientadas para uma tendência conservacionista da educação ambiental, visando principalmente a preservação da biodiversidade, da qualidade da água, dos solos e do ar. De fato, nessas propostas, raras vezes se observa a integração da educação ambiental com a política, com as artes, com a cultura popular etc.; (3) A educação ambiental parece estar sendo instituída sem um enfrentamento teórico-metodológico da problemática da formação docente em serviço.

$\mathrm{O}$ advento da educação ambiental traz à tona a percepção inteira do ambiente, questionando o especialismo cartesiano. Entretanto, essas poucas

${ }^{10}$ Em vários pontos do país, a disciplina está implantada ou em fase de implantação. $\mathrm{Na}$ região Sul, os municípios de Cascavel (PR), Caxias do Sul (SC), Cruz Alta (RS) etc. Na Região Nordeste, os municípios de Santa Cruz do Capibaribe (PE) e Tibau do Sul (RN), entre outros. No Sudeste, os municípios de Espírito Santo do Pinhal (SP), Bambuí (MG) etc. 
palavras podem esconder a complexidade do tempo presente, no qual é possível até mesmo encontrar projetos de lei prontos na internet, orientando a inclusão da disciplina na Educação Básica. Nos próximos anos, que serão importantíssimos nesse panorama que se estrutura, a pesquisa sobre a educação ambiental no contexto escolar pode e deve dar sua contribuição para que a temática possa ser institucionalizada na educação formal a partir de bases mais consistentes com as exigências deste e do tempo futuro.

\section{Consolidando e ampliando nossas discussões}

Após a exposição e discussão dos dados apresentados neste texto, alguns temas foram destacados pelos integrantes do GDP e devem ser considerados nas pesquisas em educação ambiental no contexto escolar. São eles:

1. A imersão no contexto educativo para uma apreensão abrangente da educação ambiental na escola. Essa imersão deve abranger o Projeto Político-Pedagógico da escola;

2. A compreensão da concepção de educação, individual e coletiva, como elemento importante na educação ambiental;

3. Compreensão ampla dos desdobramentos da disciplina educação ambiental na Educação Básica;

4. Credibilidade da pesquisa no contexto escolar a partir do retorno dos dados das pesquisas;

5. Compreensão da epistemologia com ênfase na teoria da complexidade;

6. A identificação das grandes questões de pesquisa no contexto escolar para então buscar métodos que forneçam respostas.

A preocupação com as abordagens teórico-metodológicas das pesquisas em educação ambiental no âmbito geral e no contexto escolar foi constante nas discussões do grupo, culminando, naquele momento, na construção de um quadro com dados das pesquisas concluídas e em andamento dos participantes do GDP, cuja análise apresentamos a seguir.

Os participantes apresentaram suas pesquisas enfocando quatro aspectos: (1) foco da pesquisa; (2) tipo da pesquisa; (3) referencial teórico e (4) aprofundamentos, sendo este último um espaço livre para questionamentos gerais sobre a própria pesquisa. Enfatizamos que não se trata de uma pesquisa formal, mas de um levantamento dentro do processo de configuração do referido Grupo de Discussão de Pesquisas. 
Em relação ao foco da pesquisa, nossa primeira percepção foi que a maior parte das temáticas estava de fato relacionada à Educação Básica, o que chama nossa atenção para a opção feita pelos participantes em fazer parte do referido grupo. Os principais focos foram os estudos da teoria da complexidade, as concepções prévias de alunos e professores, os projetos de educação ambiental, como a Agenda 21, a institucionalização da disciplina Educação Ambiental na Educação Básica e o estudo sobre práticas docentes e estratégias didáticas. Outros focos apareceram de forma mais isolada, como mídia e educação ambiental, educação ambiental no ensino técnico e percepção ambiental a partir de tema gerador.

O referencial teórico adotado pelos pesquisadores acompanha a diversidade de temáticas apresentadas e, sobretudo, revela múltiplas visões de mundo, o que é próprio da educação ambiental brasileira. Essa multiplicidade é visível na opção pelos pensadores: Paulo Freire, Carlos Frederico Loureiro, Marília Tozoni-Reis, Gerd Bornheim, Isabel Carvalho, e Edgar Morin. Além da esperada predominância da educação ambiental crítica transformadora, chama nossa atenção a presença da teoria do currículo de Ivor Goodson, bem como da teoria do discurso de Mikhail Bakhtin, atendendo uma antiga reivindicação para que o campo da educação ambiental amplie suas bases de análise.

Em relação ao tipo de pesquisa, a abordagem qualitativa aparece como um grande guarda-chuva dentro do qual figuram os estudos de caso, a pesquisa etnográfica, a pesquisa documental e a pesquisa-ação. Lembramos que a abordagem qualitativa na pesquisa no campo da educação ambiental foi uma recomendação do GDP no III EPEA e tem sido aceita por esse campo, como podemos observar nos levantamentos realizados no banco de dados da CAPES e do Caderno de Resumos do IV EPEA, os quais foram apresentados anteriormente. A opção pela pesquisa qualitativa também aparece nos trabalhos apresentados em EPEAs anteriores e em encontros de pesquisa que evolvem a pesquisa no campo da educação ambiental (TEIXEIRA et al., 2007). A baixa frequência da pesquisa-ação pode estar relacionada com os aspectos ressaltados por este mesmo GDP como a resistência dos pesquisadores a adentrar os espaços escolares, a não aceitação da escola em ser pesquisada, resistência dos professores a cooperar com as pesquisas, a dificuldade com os protocolos dos Comitês de Ética etc.

De fato, no aspecto aprofundamentos, a dificuldade de verificação in loco das práticas escolares e a dificuldade do trabalho com os professores são citadas ao lado de outras limitações, como a compreensão do processo de pesquisar e o problema em lidar com conceitos específicos, tais como disciplina, educação não formal, entre outros. Questões como essas foram apontadas no GDP do II 
EPEA, mostrando que ainda não foram superadas pelos pesquisadores da área ou que são questões próprias do campo de pesquisa em educação ambiental.

A exposição das pesquisas dos participantes coloca o GDP não apenas como um espaço de consolidação da pesquisa em educação ambiental no contexto escolar mas como um espaço privilegiado de discussão das dúvidas e inquietações relativas às pesquisas realizadas pelo grupo. Como o evento agrega participantes de diferentes regiões do país, possibilita uma troca, um intercâmbio em torno da problemática teórico-metodológica das pesquisas em educação ambiental no contexto escolar.

Terminamos nossa reflexão polemizando uma questão muito presente no GDP: a preocupação dos pesquisadores com o retorno dos resultados das pesquisas às escolas, especialmente às da Educação Básica. Esse retorno de alguma maneira reflete as pesquisas apresentadas e discutidas no GDP - não estamos nos referindo apenas às pesquisas apresentadas pelo grupo, mas às pesquisas apresentadas a partir dos levantamentos no banco de dados da CAPES, dos EPEAs anteriores, do Inep e de outros encontros de pesquisa em educação. Para iniciar a discussão sobre o tema do GDP, nos baseamos na análise de uma fotografia de uma escola preocupada com a educação ambiental, mas as ações desenvolvidas nessa escola só foram compreendidas quando a conhecemos de mais perto. Nossa pretensão em comentar essa escola visou justamente mostrar a necessidade de o pesquisador vivenciar o contexto escolar para dar conta de responder a inúmeros questionamentos presentes nesse espaço tão complexo. Pesquisas envolvendo o contexto escolar necessitam de uma proximidade maior do pesquisador com a escola? Estaria assim resolvido o problema do retorno da pesquisa para a escola? Pensamos ser essa a grande questão da pesquisa em educação ambiental no contexto escolar.

\section{Referências}

AMORIM, Antonio Carlos. Fotografia, som e cinema como afectos e perceptos no conhecimento da escola. Teias, Rio de Janeiro, ano 8, n. 15-16, 2007.

CAVALARI, Rosa Maria Feiteiro; SANTANA, Luiz Carlos; CARVALHO, Luiz Marcelo de. Concepções de educação ambiental nos trabalhos do I EPEA. Pesquisa em Educação Ambiental, São Carlos, v. 1, n. 1, p. 141-173, jul./dez. 2006.

DANIEL, Michele H.; MARIN, Andreia A. Referenciais teórico-metodológicos nas pesquisas em Educação ambiental no ambiente escolar. In: ENCONTRO DE PESQUISA EM EDUCAÇÃO AMBIENTAL, 4., 2007. Rio claro. Coletânea. Rio Claro: [s.n.], 2007. (CD-ROM). 
GUERRA, Antonio Fernando Silveira; GUIMARÃES, Mauro. Educação ambiental no contexto escolar: questões levantadas no GDP. Pesquisa em Educação Ambiental, Ribeirão Preto, v. 2, n. 1, p. 155-167, jan./jun. 2007.

GUIMARÃES, Leandro Belinaso. A invenção de dispositivos pedagógicos indagativos sobre o ambiente. In: CONGRESSO DA ASSOCIAÇÃO INTERNACIONAL PARA PESQUISA INTERCULTURAL (ARIC), 12., 2009. Florianópolis. Anais... Florianópolis: ARIC, 2009. v. 1, p. 1-13.

KAWASAKI, Clarice Sumi; MATOS, Mauricio dos Santos; MOTOKANE, Marcelo Tadeu. O perfil do pesquisador em educação ambiental: elementos para um estudo sobre a constituição de um campo de pesquisa em educação ambiental. Pesquisa em Educação Ambiental, São Carlos, v. 1, n. 1, p. 111-140, jul./dez. 2006.

LIMA, Maria Jaqueline G. Soares de. O que fazem as escolas que fazem educação ambiental no Rio de Janeiro? Uma análise da pesquisa realizada pelo MEC/UFRJ/ANPEd à luz da teorização curricular. In: REUNIÃO DA ASSOCIAÇÃO NACIONAL DE PESQUISA EM EDUCAÇÃO (ANPEd), 30., 2007. Caxambu. Anais... Caxambu: ANPEd, 2007. p. 1-17.

LORENZETTTI, Leonir; DELIZOICOV, Demetrio. Educação Ambiental: um olhar sobre dissertações e teses. Revista Brasileira de Pesquisa em Educação em Ciências, v. 6, p. 25$56,2006$.

SILVA, Luciano Fernandes; GOMES, Maria Margarida. A pesquisa em educação ambiental no contexto escolar: contribuições para uma reflexão. Pesquisa em Educaşão Ambiental, Rio Claro, v. 3, n. 1, p. 239-256, 2008.

TEIXEIRA, Lucas André; NEVES, Juliana Pereira; SILVA, Fabiane de Paula; TOZONI-REIS, Marília Freitas de Campos; NARDI, Roberto. Referenciais teóricos da pesquisa em educação ambiental em trabalhos acadêmicos. In: ENCONTRO NACIONAL DE PESQUISA EM EDUCAÇÃO EM CIÊNCIAS (EPEC), 6., 2007. Florianópolis. Anais... Florianópolis: EPEC, 2007. v. 1, p. 1-12.

TRAJBER, Rachel; MENDONÇA, Patrícia Ramos (Org.). Educação na diversidade: o que fazem as escolas que dizem que fazem educação ambiental. Brasília: Secretaria de Educação Continuada, Alfabetização e Diversidade, 2006.

TRISTÃO, Martha. Saberes e fazeres da Educação Ambiental no cotidiano escolar. Revista Brasileira de Educação Ambiental, Brasília, n. 0, p. 47-55, 2004.

VEIGA, Alinne; AMORIM, Érica; BLANCO, Mauricio. Um retrato da presença da educação ambiental no ensino fundamental brasileiro: o percurso de um processo acelerado de expansão. Brasília: MEC; Inep, 2005.

WUNDER, Alik. Foto quase grafias: o acontecimento por fotografias de escola. 2008. 127 f. Tese (Doutorado em Educação) - Faculdade de Educação, Universidade Estadual de Campinas, Campinas, 2008.

Artigo: recebido em 24/11/2009 - aprovado em 21/12/2009 